\title{
EFEITO DA CARACTERÍSTICA A ALTA TEMPERATURA DE SINTER FEEDS NA SINTERIZAÇÃO*
}

\author{
Thiago Pinto Silva ${ }^{1}$ \\ Renata Cristina Alves Elias ${ }^{2}$ \\ Beatriz Fausta Gandra ${ }^{3}$
}

\section{Resumo}

Este estudo teve como objetivo investigar o efeito da adição de minérios com diferentes comportamentos a alta temperatura (assimilação e penetração de fase líquida) nos indicadores de processo em uma sinterização piloto. Para isso, seis sinter feeds foram caracterizados e, em seguida, submetidos ao ensaio de sinterização, considerando diferentes misturas a sinterizar. Foi observado que a substituição parcial de um minério que possui grande capacidade de assimilação por aqueles que assimilam pouco o líquido formado no processo de sinterização, resultou em maior resistência mecânica do sínter. Essa propriedade pode também ser associada ao formato dos poros no sínter produto, que reflete na sua redutibilidade. Em termos de penetração de fase líquida, os resultados indicam relação direta com a resistência mecânica do sínter. Dessa forma, esses ensaios de caracterização, juntamente com os aspectos mineralógicos, químicos e granulométricos, permitem subsidiar a tomada de decisão para a substituição mais adequada de um minério na mistura a sinterizar.

Palavras-chave: Assimilação; Sinter feed; Penetração de fase líquida; Sinterização.

\section{EFFECT OF HIGH TEMPERATURE BEHAVIOR OF SINTER FEEDS ON SINTERING}

\section{Abstract}

This study aimed to investigate the effect of sinter feeds with different behaviors at high temperature (assimilation and melt penetration) in a pilot sintering. Six iron ores were characterized and then subjected to sintering test, considering different mixtures. It was observed that partial replacement of one ore with has a great ability to assimilate by those with have poor ability to assimilate the liquid formed in the sintering process, resulted in higher strength of the sinter. This property can also be linked to type of pores in the sinter product, which reflects in its reducibility. In terms of melt penetration, the results indicate a direct relationship with the sinter's mechanical strength. Therefore, these characterization tests along with the mineralogical, chemical and grain size features allow support the most appropriate decision to substitute the iron ore in the mix.

Keywords: Assimilation; Sinter feed; Melt penetration; Sintering.

1 Membro da ABM; Engenheiro Metalurgista, Pesquisador, Centro de Tecnologia Usiminas; Ipatinga, MG, Brasil.

2 Membro da ABM; Engenheira Química, M.Sc., Pesquisadora, Centro de Tecnologia Usiminas; Ipatinga, MG, Brasil.

3 Membro da ABM; Engenheira Metalurgista, M.Sc., Pesquisadora, Centro de Tecnologia Usiminas; Ipatinga, MG, Brasil. 


\section{INTRODUÇÃO}

De maneira geral, tem-se observado as sinterizações brasileiras trabalhando com minérios de qualidade inferior devido à elevação da exploração de itabiritos. Neste contexto, o conhecimento das propriedades intrínsecas dos minérios de ferro se torna fundamental para avaliar sua influência no comportamento da carga metálica, tanto na sinterização quanto no alto-forno. No caso da sinterização, a definição da mistura de minérios adequada passa a ser um vetor importante para minimização dos possíveis prejuízos operacionais.

Tradicionalmente, a Usiminas caracteriza o sinter feed por meio de suas propriedades básicas (composição química, granulométrica e mineralógica). Recentemente, o comportamento em altas temperaturas (propriedades metalúrgicas) passou a ser avaliado por meio dos ensaios assimilação e penetração de fase líquida, desenvolvidos pela Nippon Steel \& Sumitomo Metal Corporation (NSSMC). As propriedades do líquido formado na sinterização e suas consequências na estrutura do sínter vêm sendo estudadas por diversos autores [1-5], visando encontrar a utilização mais adequada do minério na sinterização.

O presente trabalho teve como objetivo investigar, em escala piloto de sinterização, o comportamento de misturas de minérios com desempenhos diferenciados em alta temperatura.

\section{MATERIAIS E MÉTODOS}

Seis minérios, cujas características químicas, granulométricas e mineralógicas são apresentadas nas Tabelas 1 a 4 , foram usados para fabricar seis misturas, substituindo o minério A por outro em $20 \%$, sendo A considerado a referência. As características básicas químicas, granulométricas e mineralógicas dessas misturas calculadas por média ponderada são apresentadas nas Tabelas 5 a 7 .

Tabela 1. Composição química dos minérios estudados (\% em massa)

\begin{tabular}{cccccc}
\hline Minério & $\mathbf{F e}_{\mathbf{T}}$ & $\mathbf{F e O}$ & $\mathbf{S i O}_{\mathbf{2}}$ & $\mathbf{A l}_{\mathbf{2}} \mathbf{O}_{3}$ & $\mathbf{P P C}$ \\
\hline $\mathrm{A}$ & 63,3 & 2,9 & 6,1 & 0,7 & 2,2 \\
\hline $\mathrm{B}$ & 66,1 & 1,6 & 2,9 & 0,8 & 0,3 \\
\hline $\mathrm{C}$ & 61,3 & 0,2 & 6,9 & 1,3 & 2,4 \\
\hline $\mathrm{D}$ & 63,9 & 0,1 & 4,7 & 1,4 & 0,8 \\
\hline $\mathrm{E}$ & 59,1 & 0,3 & 5,7 & 1,9 & 5,8 \\
\hline $\mathrm{F}$ & 66,8 & 0,3 & 3,0 & 0,6 & 0,2 \\
\hline
\end{tabular}

Tabela 2. Distribuição granulométrica dos minérios estudados (\% em massa)

\begin{tabular}{cccccc}
\hline Minério & $\mathbf{> 6 , 3 5} \mathbf{~ m m}$ & $\mathbf{( 6 , 3 5 ~ 1 ) ~} \mathbf{~ m m}$ & $\mathbf{( 1 \sim 0 , 5 )} \mathbf{~ m m}$ & $\mathbf{( 0 , 5 ~ 0 , 1 0 5 )} \mathbf{~ m m}$ & $<\mathbf{0 , 1 0 5} \mathbf{~ m m}$ \\
\hline A & 4,9 & 26,5 & $\mathbf{7 , 6}$ & $\mathbf{2 8 , 8}$ & 32,2 \\
\hline B & 2,5 & 18,9 & 32,1 & 46,0 & 0,5 \\
\hline C & 11,2 & 52,4 & 8,2 & 14,8 & 13,4 \\
\hline D & 20,7 & 22,5 & 3,6 & 22,2 & 31,0 \\
\hline E & 40,4 & 37,9 & 1,8 & 3,6 & 16,3 \\
\hline F & 0,3 & 10,7 & 4,1 & 66,2 & 18,7 \\
\hline
\end{tabular}

Tabela 3. Porosidade da fração $2,0 \mathrm{~mm}$ a $2,8 \mathrm{~mm}$ dos minérios

\begin{tabular}{lcccccc}
\hline Minério & A & B & C & D & E & F \\
\hline Porosidade (\%) & 33,2 & 5,9 & 24,6 & 10,8 & 39,9 & 8,1 \\
\hline
\end{tabular}


Tabela 4. Composição mineralógica dos minérios estudados (\% em massa)

\begin{tabular}{lccc}
\hline Minério & Hematita & Magnetita & Goethita \\
\hline A & 73,0 & 5,6 & 21,4 \\
\hline B & 95,9 & 4,1 & 0,0 \\
\hline C & 80,5 & 2,4 & 17,1 \\
\hline D & 98,1 & 0,0 & 1,9 \\
\hline E & 52,4 & 0,9 & 46,7 \\
\hline F & 99,3 & 0,5 & 0,2 \\
\hline
\end{tabular}

Tabela 5. Composição química das misturas de minérios (\% em massa)

\begin{tabular}{lccccc}
\hline Mistura de minérios & $\mathbf{F e}$ & $\mathbf{F e O}$ & $\mathbf{S i O}_{2}$ & $\mathbf{A l}_{\mathbf{2}} \mathbf{O}_{3}$ & $\mathbf{P P C}$ \\
\hline $100 \%$ A (referência) & 63,3 & 2,9 & 6,1 & 0,7 & 2,2 \\
\hline $80 \%$ A e 20 \% B & 63,9 & 2,6 & 5,5 & 0,7 & 1,8 \\
\hline $80 \%$ A e 20 \% C & 62,9 & 2,4 & 6,3 & 0,8 & 2,2 \\
\hline $80 \%$ e e 20 \% D & 63,4 & 2,3 & 5,8 & 0,8 & 1,9 \\
\hline $80 \%$ A e 20 \% E & 62,5 & 2,4 & 6,0 & 0,9 & 2,9 \\
\hline $80 \%$ A e 20 \% F & 64,0 & 2,4 & 5,5 & 0,7 & 1,8 \\
\hline
\end{tabular}

Tabela 6. Distribuição granulométrica das misturas de minérios (\% em massa)

\begin{tabular}{lccccc}
\hline Mistura de minérios & $\begin{array}{c}\mathbf{> 6 , 3 5} \\
\mathbf{m m}\end{array}$ & $\begin{array}{c}\mathbf{( 6 , 3 5 ~ 1 )} \\
\mathbf{m m}\end{array}$ & $\begin{array}{c}\mathbf{( 1 \sim 0 , 5 )} \\
\mathbf{m m}\end{array}$ & $\begin{array}{c}\mathbf{( 0 , 5 ~ 0 , 1 0 5 )} \\
\mathbf{m m}\end{array}$ & $\begin{array}{c}<\mathbf{0 , 1 0 5} \\
\mathbf{m m}\end{array}$ \\
\hline $100 \% \mathrm{~A}$ & 4,0 & 23,3 & 6,9 & 36,3 & 29,5 \\
\hline $80 \% \mathrm{~A} \mathrm{e} 20 \% \mathrm{~B}$ & 4,0 & 23,3 & 6,9 & 36,3 & 29,5 \\
\hline $80 \% \mathrm{~A} \mathrm{e} 20 \% \mathrm{C}$ & 8,1 & 25,7 & 6,8 & 27,5 & 32,0 \\
\hline $80 \% \mathrm{~A} \mathrm{e} 20 \% \mathrm{D}$ & 12,0 & 28,8 & 6,4 & 23,8 & 29,0 \\
\hline $80 \% \mathrm{~A} \mathrm{e} 20 \% \mathrm{E}$ & 4,4 & 25,0 & 12,5 & 32,2 & 25,9 \\
\hline $80 \% \mathrm{~A} \mathrm{e} 20 \% \mathrm{~F}$ & 6,2 & 31,7 & 7,7 & 26,0 & 28,4 \\
\hline
\end{tabular}

Tabela 7. Composição mineralógica da mistura de minérios (\% em massa)

\begin{tabular}{lccc}
\hline Mistura de minérios & Hematita & Magnetita & Goethita \\
\hline $100 \%$ A & 73,0 & 5,6 & 21,4 \\
\hline $80 \%$ A e $20 \%$ B & 77,6 & 5,3 & 17,1 \\
\hline $80 \%$ A e $20 \%$ C & 74,5 & 5,0 & 20,5 \\
\hline $80 \%$ A e $20 \%$ D & 78,0 & 4,5 & 17,5 \\
\hline $80 \%$ A e $20 \%$ E & 68,9 & 4,7 & 26,5 \\
\hline $80 \%$ A e $20 \%$ F & 78,3 & 4,6 & 17,2 \\
\hline
\end{tabular}

\subsection{Assimilação com CaO}

A assimilação dos minérios com o $\mathrm{CaO}$ foi avaliada considerando a configuração da quase partícula que pode ser dividida em duas regiões: nucleante e aderente.

A reação entre minério e calcário na região nucleante foi avaliada por meio da preparação de quase partículas, aglomerando com água o minério $(2,0 \mathrm{~mm}$ a $2,8 \mathrm{~mm}$ ) com o undersize do calcário classificado em $0,5 \mathrm{~mm}$ (Figura 1a). A relação entre as duas matérias-primas ( $\mathrm{CaO} /$ minério) foi 0,1 . Os agregados foram adicionados num cadinho de níquel e aquecidos ao ar até $1300^{\circ} \mathrm{C}$, sendo de $1100^{\circ} \mathrm{C}$ a $1300^{\circ} \mathrm{C}$ em $1 \mathrm{~min}$ e no resfriamento, também ao ar, de $1300^{\circ} \mathrm{C}$ a $1100^{\circ} \mathrm{C} \mathrm{em} 3 \mathrm{~min}$. Foi fabricado um corpo de prova para análise ao microscópio óptico.

A outra região (aderente) foi avaliada misturando com água os undersizes do minério e do calcário classificados em $0,5 \mathrm{~mm}$; mantendo a relação entre as duas matérias-primas ( $\mathrm{CaO} /$ minério) igual a 0,1 . A mistura foi compactada a $2 \mathrm{MPa}$ durante $30 \mathrm{~s}$, produzindo um corpo de prova cilíndrico (Figura 1b). O processamento térmico foi o mesmo realizado para às quase partículas. Neste caso, quatro corpos de prova foram fabricados, um para avaliação ao microscópio óptico e três para medição da resistência mecânica. Essa medição foi realizada deixando cair três 
vezes um peso com $300 \mathrm{~g}$ na amostra de sínter e em seguida classificando-o em peneiras. $O$ índice foi calculado pela porcentagem retida na malha de $0,5 \mathrm{~mm}$.

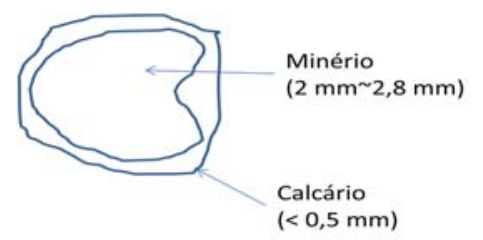

(a) quase partículas

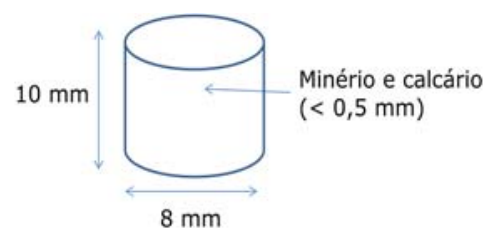

(b) tablet

Figura 1. Desenho esquemático dos corpos de prova do ensaio assimilação.

O processo térmico foi realizado em um dilatômetro de haste horizontal, sendo adaptado para o ensaio assimilação (Figura 2).
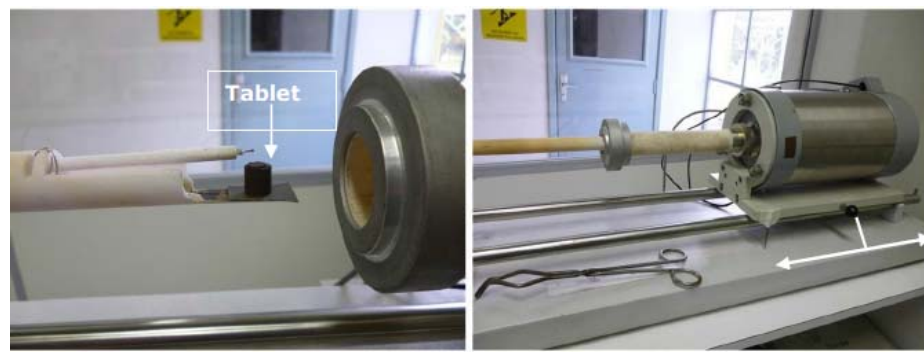

Figura 2. Detalhes do dilatômetro com haste horizontal adaptado para o ensaio assimilação.

A amostra destinada a análise microscópica foi embutida em resina de cura lenta, cortada conforme desenhos esquemáticos mostrados nas Figuras 3a e 3b, frações nucleante e aderente, respectivamente, e levada à politriz semiautomática.

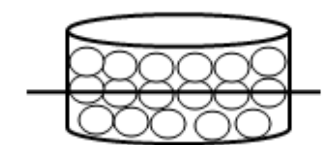

(a) fração nucleante

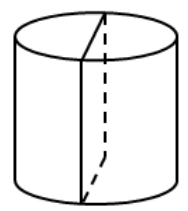

(b) fração aderente

Figura 3. Detalhes do corte nos corpos de prova do ensaio assimilação.

\subsection{Penetração de Fase Líquida}

O espalhamento do líquido na região aderente da quase partícula foi avaliado pela medição da sua profundidade de penetração. Na Figura 4 são mostrados os corpos de prova, sendo um de minério (undersize classificado em $0,5 \mathrm{~mm}$ ) e o outro fabricado com os reagentes químicos $\mathrm{Fe}_{2} \mathrm{O}_{3}$ e $\mathrm{CaO}$, esse último, simulando a cálcio ferrita.

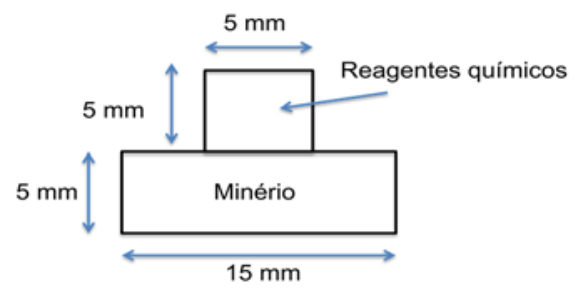

Figura 4. Desenho esquemático dos corpos de prova do ensaio penetração de fase líquida.

O primeiro corpo de prova, que serviu de base, foi fabricado misturando o minério com água durante $30 \mathrm{~s}$. Em seguida, fez-se a prensagem dessa mistura a $2 \mathrm{MPa}$ por 
$30 \mathrm{~s}$. O outro corpo de prova foi fabricado misturando os reagentes químicos $\mathrm{Fe}_{2} \mathrm{O}_{3}$ e $\mathrm{CaO}$ em um grau de ágata durante $2 \mathrm{~min}$, seguindo a relação $\mathrm{CaO} / \mathrm{Fe}_{2} \mathrm{O}_{3}$ igual a 0,35 . Esta mistura foi prensada a $2 \mathrm{MPa}$ por $30 \mathrm{~s}$. O processo térmico foi igual aquele realizado no ensaio assimilação, produzindo-se uma amostra para análise ao microscópio óptico.

A amostra do ensaio penetração de fase líquida foi cortada ao meio longitudinalmente, sendo preparada para análise ao microscópio óptico, no qual se mediu o comprimento de penetração, usando um software específico. Para isso foi adotada a metodologia proposta por Okazaki et al. [1], em que se marca cinco posições no corpo de prova e se mede o comprimento do centro e a $1 / 4$ de distância do centro, conforme mostrado na Figura 5 . O valor médio dessas posições expressa o comprimento de penetração da fase líquida do ensaio.

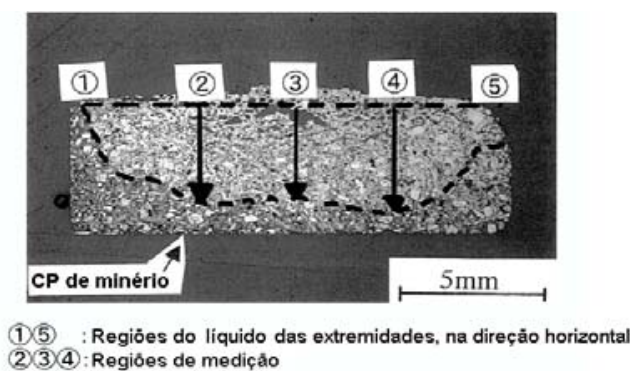

Figura 5. Determinação do comprimento de penetração (adaptado de Okazaki et al. [1]).

\subsection{Ensaio Sinterização Piloto}

Os parâmetros usados no ensaio sinterização são apresentados na Tabela 8.

Tabela 8. Parâmetros do ensaio sinterização piloto.

\begin{tabular}{|c|c|}
\hline Parâmetros & Valor \\
\hline Altura da camada & $520 \mathrm{~mm}$ \\
\hline Diâmetro da panela & $300 \mathrm{~mm}$ \\
\hline Relação ar/COG (Coke Oven Gas) & 5,2 \\
\hline Altura do bedding & $30 \mathrm{~mm}$ \\
\hline Massa do bedding & $3 \mathrm{~kg}$ \\
\hline Tempo de ignição & $1 \mathrm{~min}$ \\
\hline Depressão durante ignição & $600 \mathrm{mmH}_{2} \mathrm{O}$ \\
\hline Depressão durante a queima & $1500 \mathrm{mmH}_{2} \mathrm{O}$ \\
\hline Depressão durante o resfriamento & $800 \mathrm{mmH}_{2} \mathrm{O}$ \\
\hline Tempo de residência (misturador intensivo) & $1,4 \mathrm{~min}$ \\
\hline Rotação do elemento misturador (misturador intensivo) & 346 RPM \\
\hline Diâmetro do agitador (misturador intensivo) & $350 \mathrm{~mm}$ \\
\hline Tempo de residência (tambor aglomerador) & $6 \mathrm{~min}$ \\
\hline Rotação (tambor aglomerador) & 14 RPM \\
\hline Adição da água & $\begin{array}{c}80 \% \text { no misturador intensivo } \\
\text { e } 20 \% \text { no tambor }\end{array}$ \\
\hline Umidade & $7,0 \%$ \\
\hline Basicidade binária & 1,75 \\
\hline
\end{tabular}

Os ensaios na sinterização piloto foram conduzidos adotando o minério $A$ como referência, a qual o balanço de retorno (input/output) visado foi 1 , variando a proporção de combustível. Para as demais misturas, o combustível foi fixado no valor determinado para a mistura de referência, deixando o balanço de retorno como variável. Para a avaliação da resistência mecânica do sínter, usou-se a norma JIS M8711 [6]. 


\section{RESULTADOS E DISCUSSÃO}

\subsection{Comportamento dos Minérios em Alta Temperatura}

A macroestrutura e a microestrutura dos sínteres após assimilação da fração nucleante são mostradas nas Figuras 6 e 7, respectivamente.
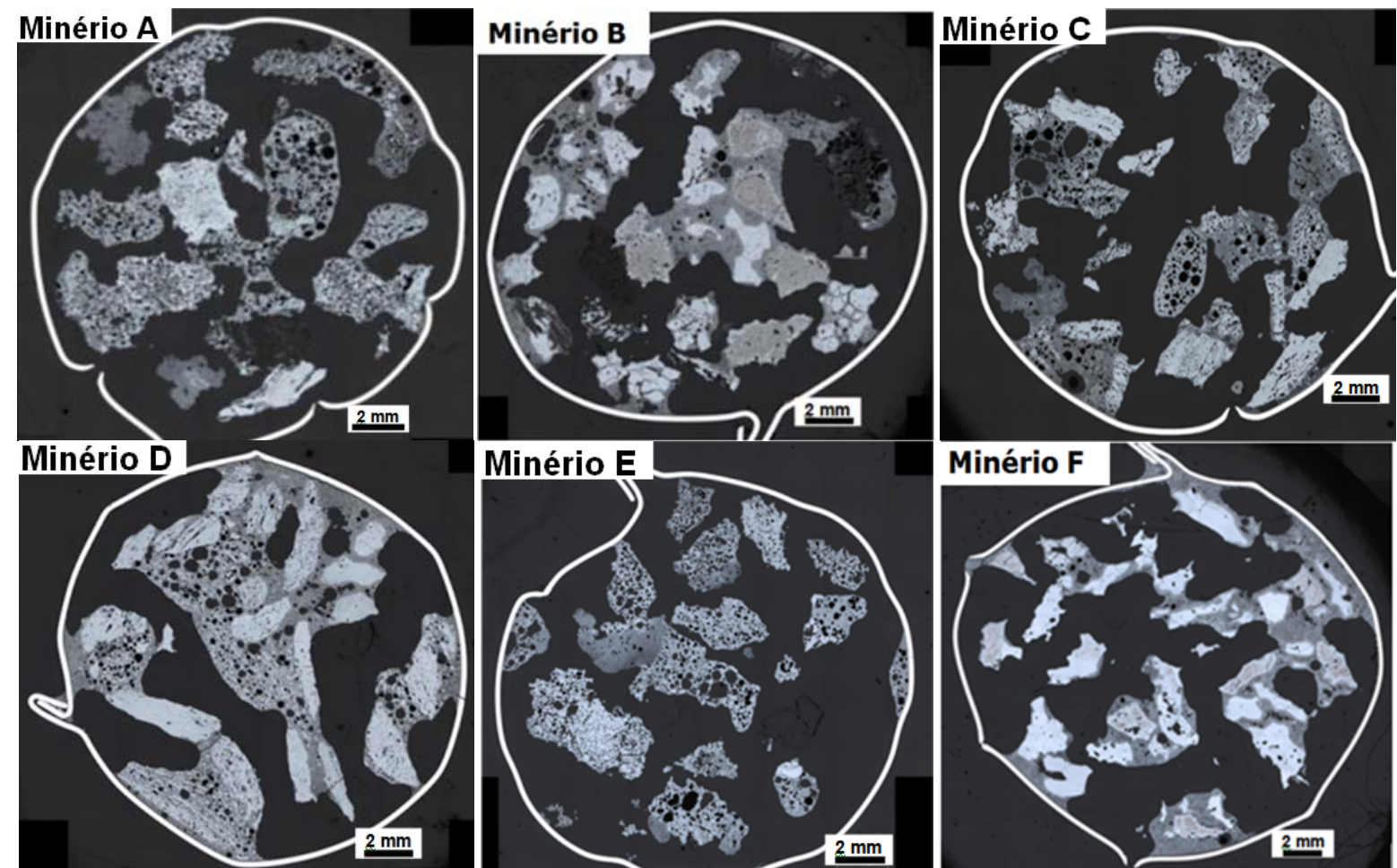

Figura 6. Macroestrutura dos sínteres após assimilação da fração nucleante do minério. (Aumento de $50 x)$.

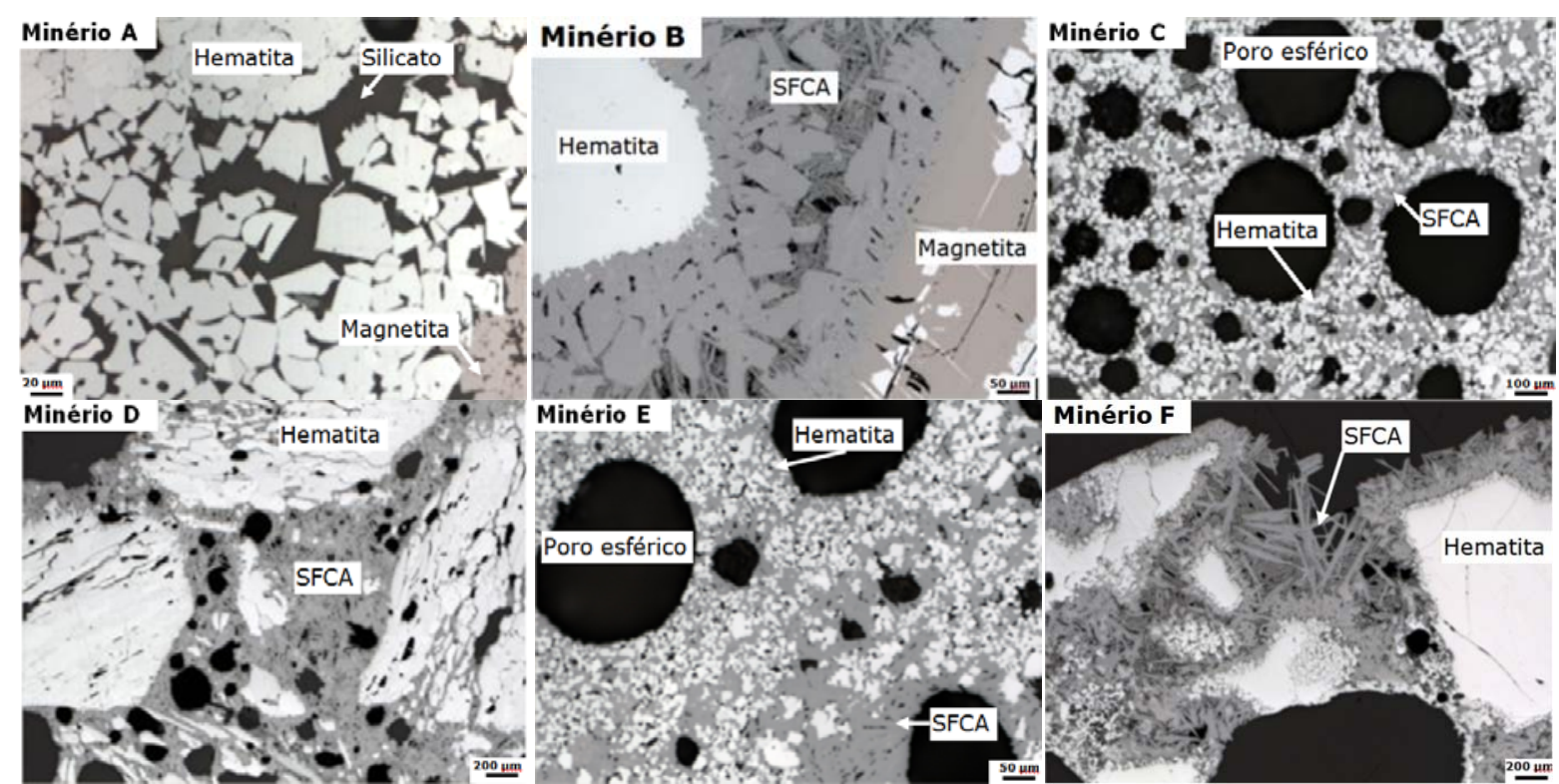

Figura 7. Microestrutura dos sínteres após assimilação da fração nucleante do minério. (Aumentos de 50x, 100x e 200x). 
Nota-se em suas macroestruturas que os minérios se comportaram de maneira diferente, sendo que $A, C$ e $E$ apresentaram partículas porosas e isoladas enquanto que $B, D$ e $F$ partículas aglomeradas. Ademais, a assimilação dos minérios $A, C$ e $E$ foi maior que $B, D$ e $F$ devido a maior porosidade dos minérios, menor fluidez $e$ menor quantidade de líquido disponível, configurando partículas isoladas.

Por sua vez, aqueles com maior porosidade assimilaram maior quantidade de líquido, resultando em menor quantidade de líquido para aglomerar outras partículas. Esses resultados concordam com aqueles apresentados por Denbricat [2].

As partículas porosas de sínter observadas em A, C e E (Figura 6) são oriundas da goethita que, por se tratar de um mineral hidratado, gera poros ao passar pela desidratação. Assim, o líquido penetra na partícula, sendo assimilado quase que por completo.

Em relação aos sínteres (Figura 6) oriundos dos minérios $B$, D e $F$ nota-se que as partículas de minérios, que foram pouco assimiladas, formaram silico-ferrite of calcium and aluminum (SFCA), servindo de ponte entre as demais partículas, estrutura considerada ideal para uma boa redutibilidade do sínter.

Ao avaliar suas microestruturas, Figura 7, nota-se a presença majoritária de SFCA ao testar os minérios $B, D$ e $F$ e de silicato para os minérios $A, C$ e $E$. Ainda é possível notar nos minérios $\mathrm{C}$ e $\mathrm{E}$ estruturas com poro esférico, pequenas hematitas e SFCA, típica de goethita assimilada.

A macroestrutura e a microestrutura dos sínteres após assimilação da fração aderente são mostradas nas Figuras 8 e 9, respectivamente.

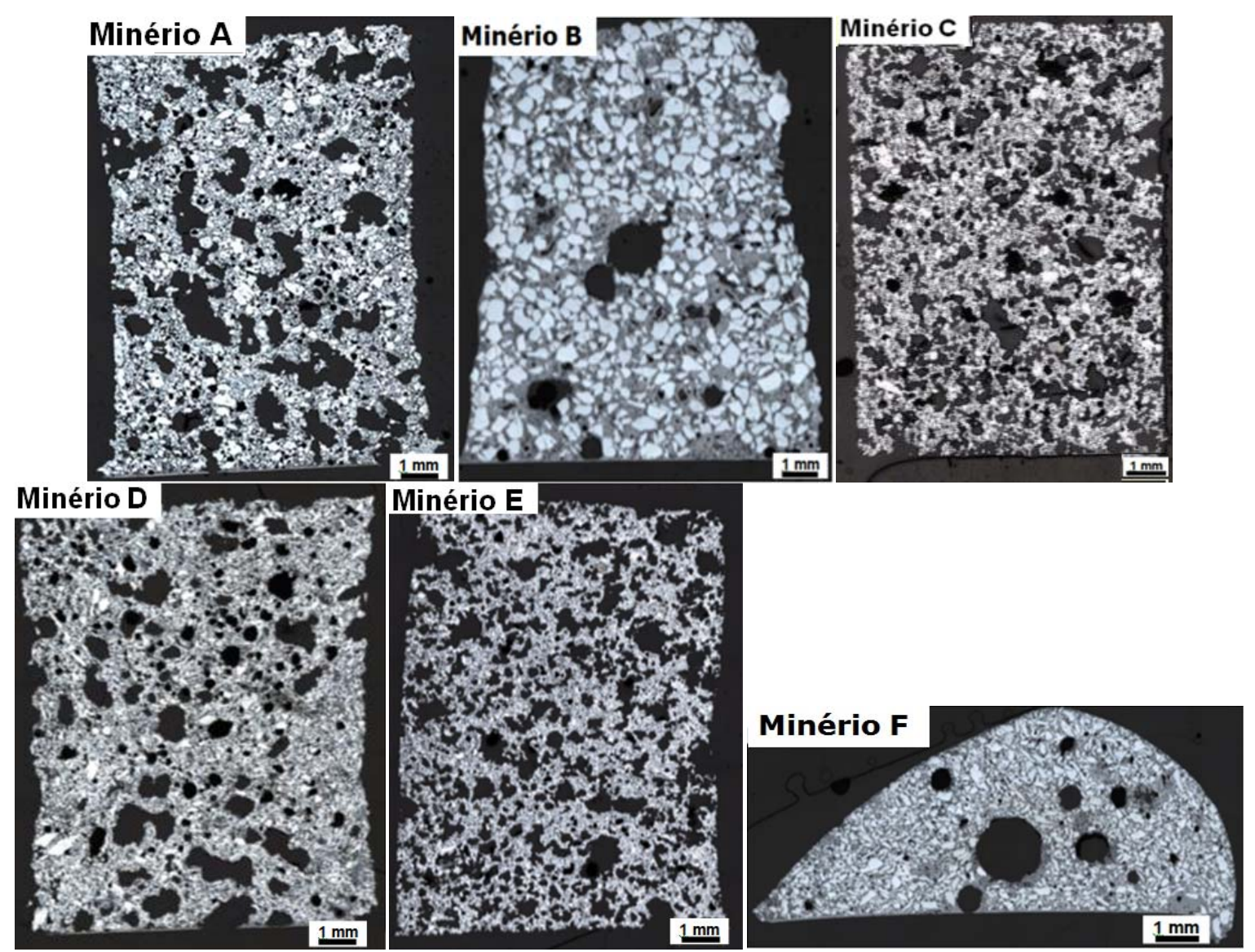

Figura 8. Macroestrutura dos sínteres após assimilação da fração aderente. (Aumento de 50x) 

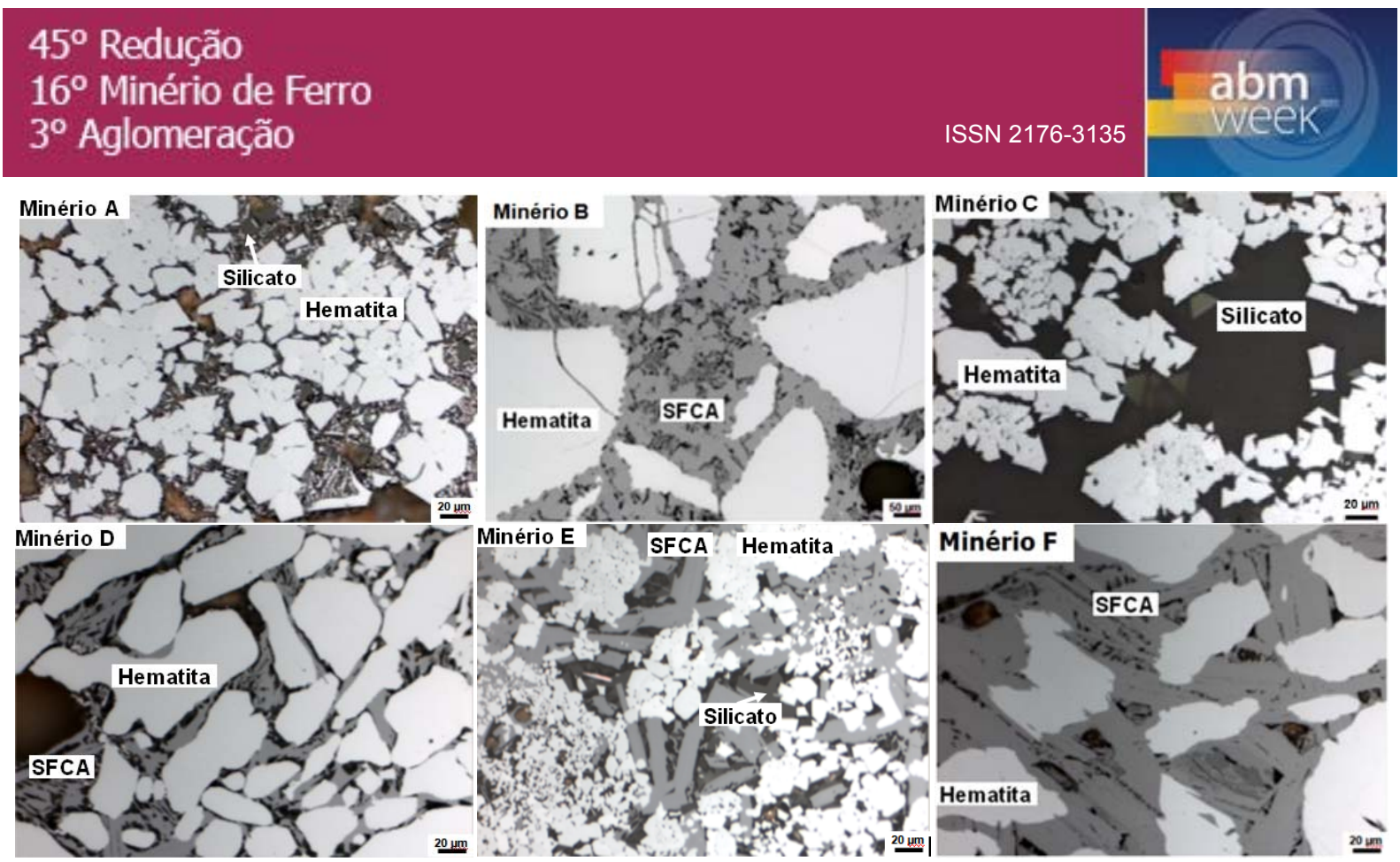

Figura 9. Microestrutura dos sínteres após assimilação da fração aderente. (Aumento de 200x e $500 x)$.

Pode-se inferir que:

- A, C e E apresentaram formatos similares e estrutura com poros irregulares;

- D apresentou uma estrutura um pouco mais compacta que aqueles citados anteriormente e com poros irregulares a esféricos;

- B apresentou uma estrutura compacta com pouco poro esférico; e,

- F apresentou formato achatado com pouco poro esférico.

O formato dos poros nestes corpos de prova (Figura 8) pode ser uma evidência da fluidez do líquido, sendo que os minérios ( $\mathrm{B}$ e $\mathrm{F}$ ) com menor teor de ganga tenderam a formar líquidos de maior fluidez e, com isso, poros esféricos. Por outro lado, minérios com maior teor de ganga $(A, C$ e $E$ ) tenderam a formar líquidos de menor fluidez, formando poros irregulares. $O$ minério $D$ que apresentou poros irregulares $e$ esféricos apresentou um líquido de fluidez intermediária.

A fração aderente dos minérios $B$ e $F$, apesar da similaridade química $e$ mineralógica, formaram sínteres com estruturas diferentes. No processo de sinterização, estes minérios formariam líquido em menor temperatura que $A, C, D$ e E contribuindo, possivelmente, para o menor consumo de combustível e maior velocidade da frente de queima.

Na Figura 10 é mostrada a resistência mecânica dos sínteres após assimilação da fração aderente. A maior resistência mecânica foi obtida pelo minério $B$ e a menor pelo minério $\mathrm{E}$.

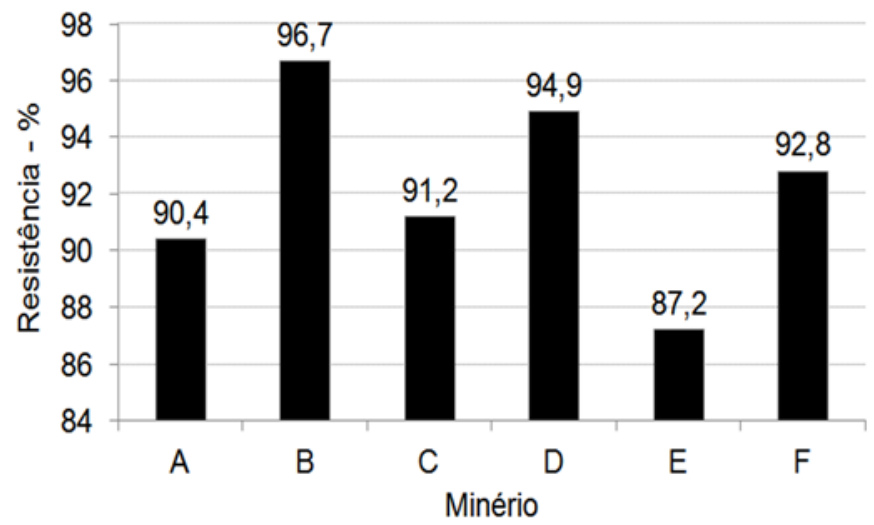

Figura 10. Resistência mecânica dos sínteres após assimilação da fração aderente do minério. 
Na Figura 11 é mostrado o comprimento da penetração de fase líquida nos minérios avaliados, exceto no minério $B$ que apresentou dificuldades em se manter rígido durante o processamento térmico. Observa-se que o minério $\mathrm{F}$ apresentou o maior índice enquanto que o minério $C$ o menor.

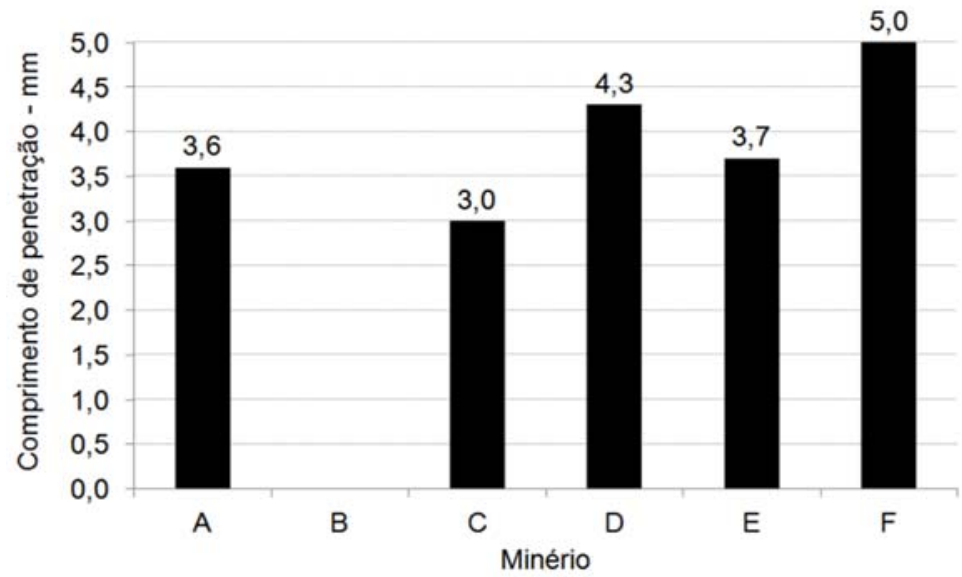

Figura 11. Comprimento da penetração do líquido nos minérios.

\subsection{Comportamento na Sinterização Piloto}

Os indicadores produtividade e Flame Front Speed (FFS) são mostrados na Figura 12 e o rendimento $(S /(S+R))$ e a resistência mecânica (shatter) do sínter na Figura 13. Os valores são relativos àqueles obtidos pela mistura $A$, tida como referência e indicada pela linha de equilíbrio (zero).

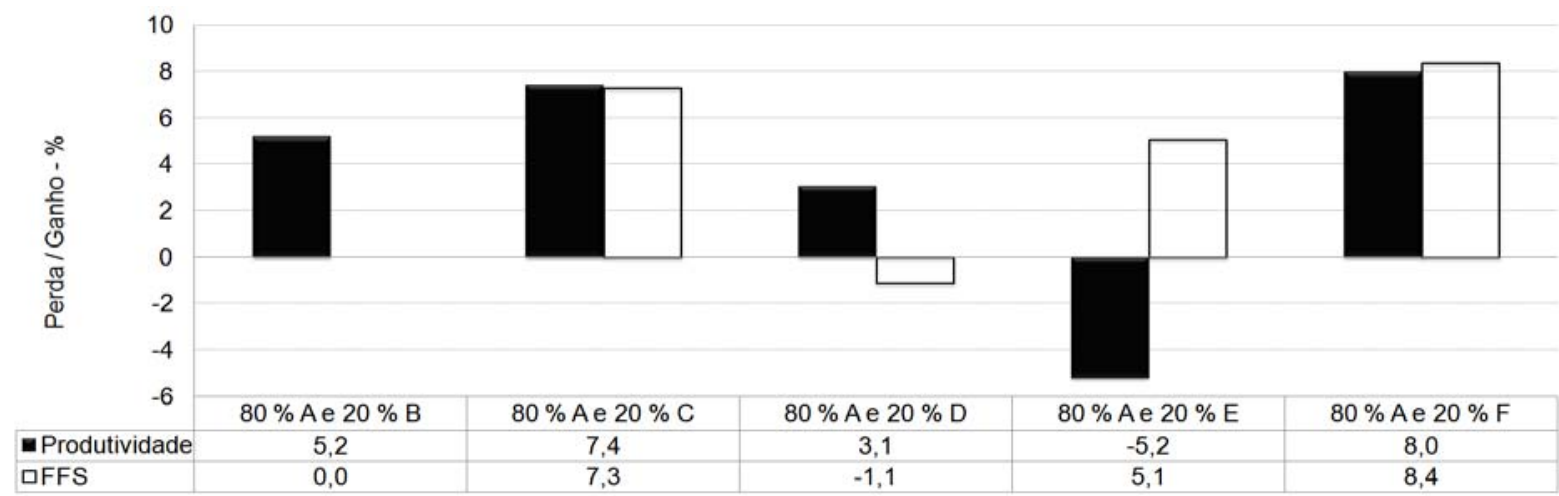

Figura 12. Comportamento dos indicadores produtividade e FFS (valores relativos).

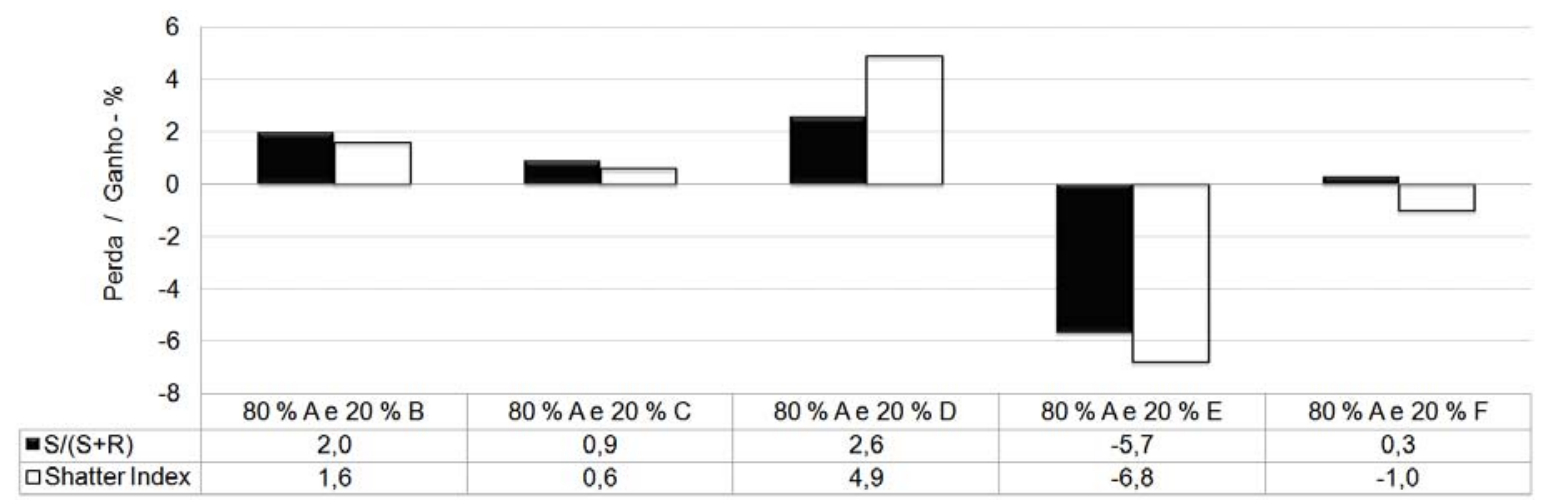

Figura 13. Comportamento dos indicadores rendimento e shatter (valores absolutos). S (Sínter) e R (Retorno) 
De maneira geral, nota-se que a substituição do minério $\mathrm{A}$ pelos demais minérios melhorou a produtividade e a resistência mecânica do sínter, exceto naquela realizada pelo sinter feed $\mathrm{E}$. As razões para tais comportamentos dos minérios são explicadas a seguir:

- B melhorou a produtividade em função do rendimento, pois a permeabilidade (FFS) foi mantida. O rendimento e a resistência mecânica do sínter foram elevados por causa dos maiores valores de resistência após assimilação e de comprimento de penetração desse minério em relação ao A;

- C melhorou a produtividade em função do aumento do FFS que, por sua vez, foi elevado em razão da maior proporção de partículas nucleantes dessa mistura. A resistência mecânica e o rendimento deste sínter foram praticamente mantidos em virtude dos valores próximos de resistência obtidos no ensaio assimilação e no ensaio comprimento de penetração em relação ao sinter feed A;

- D elevou levemente a produtividade, apesar da redução do FFS, devido à melhora do rendimento. O FFS pode ter sido influenciado negativamente pela maior proporção de partículas nucleantes e aderentes nessa mistura e, possivelmente, à inferior capacidade de aglomeração a frio deste minério. $O$ rendimento e a resistência mecânica melhoraram em razão dos valores superiores de resistência após assimilação e de comprimento de penetração ao $\mathrm{A}$;

- E reduziu drasticamente a produtividade, apesar da elevação do FFS, pois houve significativa piora do rendimento. O FFS foi alterado em consequência da maior proporção de partículas nucleantes e grossas. Ademais, a presença da goethita favorece a aglomeração a frio, contribuindo também para aumentar esse indicador. Por outro lado, o rendimento e a resistência do sínter mostraram o pior comportamento dentre os sínteres avaliados neste estudo, haja vista o fraco desempenho desse minério nos ensaios em alta temperatura; e,

- F elevou consideravelmente a produtividade em virtude da significativa elevação do FFS, sendo a maior elevação entre as misturas estudadas. A distribuição granulométrica dessa mistura (Tabela 6) mostrou elevação somente de partículas aderentes, ou seja, não houve engrossamento da mistura para justificar a elevação do FFS. Ademais, o rendimento e a resistência mecânica desse sínter foram praticamente mantidos.

No ensaio assimilação, o minério $F$ se comportou diferente dos demais apresentando formato achatado (Figura 8) por causa da grande quantidade de líquido formado. Além do mais, esse minério apresentou a maior penetração entre os minérios estudados. Esses resultados mostram que a fluidez do líquido gerado por ele é extremamente elevada e, com isso, o fluxo de ar, por não encontrar resistência, faz com que a frente de queima evolua com pouca restrição ao longo da máquina de sínter, reduzindo o tempo de sinterização, ou seja, elevando o FFS. No entanto, por sua fluidez ser elevada, o líquido difunde muito rápido entre as partículas nucleantes, reduzindo a aglomeração a quente e, consequentemente, prejudicando a resistência e rendimento. Por isso, não foi observado melhora significativa nesses dois indicadores. 


\section{CONCLUSÃO}

Foi investigado o efeito da adição de minérios com diferentes comportamentos em alta temperatura nos indicadores de processo em uma sinterização piloto. Para isso, utilizou-se o minério A como referência.

Os resultados mostraram que o desempenho do sínter (rendimento e resistência) fabricado com o minério $A$ foi melhorado com a adição de minérios $B, D$ e $F$, cujas resistências após assimilação e comprimentos de penetração foram superiores a ele devido a maior capacidade de formação de líquido com alta fluidez. A adição do minério C, cuja assimilação foi similar e penetração inferior ao $A$, elevou a produtividade devido a sua granulometria grosseira e não ao rendimento. A adição do $\mathrm{E}$, apesar da granulometria grosseira, reduziu a produtividade devido ao menor rendimento, por apresentar baixa resistência após assimilação e pouca penetração de fase líquida.

Os novos ensaios permitem explicar de maneira adequada o comportamento metalúrgico dos minérios na sinterização, se mostrando muito eficaz como complemento do ensaio de sinterização em escala piloto.

\section{Agradecimentos}

Agradecimento especial aos profissionais da NSSMC: Jun Okazaki, Yuji Fujioka e Tsumotu Okada.

\section{REFERÊNCIAS}

1 Okazaki J, Higuchi K, Hosotani Y, Shinagawa K. Influence of Iron Ore Characteristics on Penetration Behavior of Melt into Ore Layer. ISIJ International. 2003; Vol. 43 (No 9): pp. 1384-1392.

2 Debrincat D, Loo, CE, Hutchens MF. Effect of Iron Ore Particle Assimilation on Sinter Structure. ISIJ International. 2004; Vol. 44 (No 8): pp. 1308-1317.

3 Okazaki J, Nakano M, Higuchi K. Marra Mamba Ore, Its Mineralogical Properties and Evaluation for Utilization. ISIJ International. 2005; Vol. 45 (N 4): pp. 427-435.

4 Otomo T, Taguchi N, Kasai E. Suppression of the Formation of Large Pores in the Assimilated Parts of Sinter Produced Using Pisolitic Ores. ISIJ International. 1996; Vol. 36 ( $\left.N^{\circ} 11\right)$ : pp. 1338-1343.

5 Alencar JPSG, Pimenta FV, Botelho MEE, Vieira MB, Pimenta HP. Understanding the Behavior of Sinter Feeds at High Temperatures. $6^{\circ}$ International Congress on the Science and Technology of Ironmaking, ABM e ICSTI. 2012.

6 Japanese Industrial Standard. Test Method for Determination of Shatter Strength of Iron Ore Sinter. 1987, JIS M 8711,Tóquio, Japão, 4 pp. 